\title{
A questão da independência do Banco Central: uma análise do caso brasileiro
}

\author{
Juliano Vargas ${ }^{1}$ \\ Hugo Leonardo Salgado Brazil²
}

\begin{abstract}
Resumo:
$\mathrm{O}$ artigo examina a questão da independência do Banco Central do Brasil (BCB) e sua relação com o governo brasileiro. Primeiramente, são apresentados os pressupostos que conformam o arcabouço teórico da proposta de independência do Banco Central (IBC). Depois, discutem-se os principais argumentos favoráveis e contrários à independência do BCB e se existem evidências de que o governo influencia em suas decisões, bem como as possíveis implicações disso para a condução da política monetária. Conclui-se que mais importante que a concessão da referida independência é a normatização do relacionamento entre autoridade monetária, governo e setor privado, estabelecendo-se institucionalidades garantidoras da participação do BCB nas decisões governamentais.
\end{abstract}

Palavras-chave: Política Monetária. Independência do Banco Central. Banco Central do Brasil.

The issue of Central Bank independence: an analysis of the Brazilian case

\begin{abstract}
:
The article examines the question of the independence of the Brazilian Central Bank (BCB) and its relationship with the Brazilian government. Firstly, it is presented the theoretical framework that structures the proposal of Central Bank independence (IBC). After that, it will be discussed the main arguments for and against the independence of the $\mathrm{BCB}$ and if there are evidences that the government affects in its decisions, as well as the possible implications of this to the monetary policy management. It is concluded that more important than grant the IBC is the normalization of the relationship among monetary authority, government and the private sector, establishing institutionalities that grant the BCB's participation in government decisions.
\end{abstract}

Keywords: Monetary Policy. Central Bank Independence. Brazilian Central Bank.

Classificação JEL: E52, E58, N36.

1 Doutorando em Economia pela Universidade de Brasília (UnB). E-mail: brazil.juliano@gmail. com

2 Mestre em Economia pela Universidade Federal do Espírito Santo. E-mail: hugobrazil241087@ gmail.com 


\section{Introdução}

De meados da década de 1970 em diante, um grande número de países promoveu alterações no seu arcabouço institucional a fim de tornar seus bancos centrais mais independentes em relação aos seus respectivos governos. Essas mudanças apontavam que as autoridades monetárias teriam maior autonomia3 para direcionar sua atenção à finalidade primordial de estabilidade de preços, em detrimento de outros objetivos, tais como o financiamento do déficit público, o crescimento econômico, o baixo nível de desemprego, etc. Todavia, as evidências teóricas e empíricas não confirmam que isso tenha, de fato, ocorrido.

Destarte, e assumindo haver relação estreita entre política econômica e processos políticos, este artigo tem como fito apresentar e discutir a temática da independência do Banco Central do Brasil, baseando-se em uma perspectiva metodológica expositiva e analítica, de acordo com interpretações de pesquisas elaboradas por estudiosos do tema e na análise do discurso de agentes econômicos e políticos. As questões a serem discutidas são: a) Quais os pressupostos teóricos que sustentam a tese da IBC? Quais os principais argumentos favoráveis e contrários à independência do $\mathrm{BCB}$ ? c) Tem havido pressões por parte do governo federal sobre as decisões emitidas pelo $\mathrm{BCB}$ e, em caso afirmativo, como elas têm afetado a condução da política monetária no país?

O artigo segue a seguinte estrutura: na seção 2 será apresentado o arcabouço teórico que fundamenta a proposta de IBC; na seção 3 discutem-se os principais argumentos favoráveis e contrários à independência do $\mathrm{BCB}$; na seção 4 serão analisadas comparativamente duas gestões a frente do $\mathrm{BCB}$, a de Henrique de Campos Meirelles (2003-2010) e a de Alexandre Antônio Tombini (2011-2016), isso com o intuito de investigar se existiram evidências de que o Executivo e o Legislativo brasileiro agiram no sentido de pressionar e influenciar as decisões do BCB nesses dois períodos, além das possíveis implicações disso para condução da política monetária nacional.

\section{A proposta de independência do Banco Central: arcabouço teórico}

A adoção da IBC é defendida especialmente pela escola de pensamento macroeconômico novo-clássica, surgida ao longo da década de 1970 em contraposição à teoria econômica de matriz keynesiana. Segundo os novos-clássicos, o controle da inflação deve ser a única competência do banco central, o que favoreceria ao merca-

3 A autonomia do banco central refere-se ao poder deste órgão em determinar algumas regras para sua ação, o que tende a reforçar sua credibilidade perante o mercado, uma vez que não estaria a autoridade monetária atrelada a possíveis visões de curto prazo do Executivo e do Legislativo. Já a expressão independência do banco central é mais abrangente, remetendo à liberdade desta instituição em implementar políticas monetárias sem a necessidade de discussão prévia com nenhuma outra esfera de poder, já que ela não cede às pressões externas. 
do autorregulado atingir a estabilidade macroeconômica. Além disso, prognostica que o governo não deve agir de forma discricionária tanto na política fiscal quanto na política monetária.

Nesse sentido, conforme Mendonça (2003) e Moreira (2012), os novos-clássicos utilizam como pressupostos teóricos a neutralidade da moeda, as expectativas racionais, a flexibilidade perfeita de preços, a taxa natural de desemprego, o equilíbrio contínuo dos mercados e a descrença na relação de trade-off permanente entre a taxa de inflação e a taxa de desemprego estabelecidas pela Curva de Phillips ${ }^{4}$ para concluírem que a política monetária não afeta variáveis reais, gerando unicamente inflação. Tal poder de afetar variáveis reais só seria verificado em um período muito curto de tempo, e mesmo assim com restrições, pois nesse modelo os agentes não incorrem no mesmo erro sistematicamente.

Complementando essa visão, Paula (2004) diz que para coibir o viés inflacionário das autoridades monetárias, os novos-clássicos preconizam a imposição de compromissos institucionais que o inibam, de modo a fortalecer a credibilidade nas regras monetárias adotadas e garantir que a finalidade de política seja a estabilidade de preços, mesmo que sacrificando outros objetivos. É nesse sentido que se inserem as propostas do regime de metas de inflação - política econômica que objetiva manter a inflação em níveis baixos e estáveis via comprometimento explícito do banco central em perseguir um objetivo numérico fixo anunciado previamente ao público - e da independência do banco central, por garantirem, em tese, a liberdade operacional dos gestores e direcionar as atividades das autoridades monetárias ao escopo único de estabilidade de preços.

Mais explicitamente, ao analisarem a autoridade monetária, os novo-clássicos concordam que ela tende a ter um viés inflacionário já que sempre está tentada a buscar diminuir o desemprego usando um pressuposto trade-off com a inflação (KYDLAND \& PRESCOTT, 1977). As propostas incluem, então, dar maior credibilidade a autoridade monetária por meio de mecanismos como a escolha de um presidente do banco central com perfil conservador (ROGOFF, 1985) e contratos entre o banco central e o governo, para garantir que a estabilidade de preços seja a única prioridade (WALSH, 1995). Essa tese de que um banco central independente garantiria uma inflação menor e mais estável repousa sobre evidências empíricas favoráveis a ela e apontadas em estudos quantitativos e econométricos, como os de Cukierman, Webb \& Neyapti (1992) e de Alesina \& Summers (1993).

Alesina \& Summers (1993), por exemplo, apontam que criar mecanismos que concedam independência às autoridades monetárias frente ao processo político evita efeitos indesejados e auxiliam no sentido de se chegar a uma taxa de inflação dentro da meta estipulada. A lógica por detrás desse argumento centra-se na crítica aos

\footnotetext{
4 O modelo original usa uma curva de oferta baseada na Curva de Philips, em que o trade-off entre a taxa de inflação e a taxa de desemprego é verificado apenas no curto prazo. No longo prazo valerá uma curva vertical.
} 
chamados ciclos políticos, em que especialmente nos períodos próximos às eleições os governantes tendem a gastar mais, aumentando a oferta monetária e, por conseguinte, geram inflação. Por esse raciocínio, outros inconvenientes que afetariam a condução da política monetária dizem respeito à espiral preços-salários, à marcação de preços e ao jogo ininterrupto entre autoridades e agentes. Com independência, um banco central poderia simultaneamente estabilizar o nível de preços e disciplinar os gastos governamentais (ALESINA, 1989; ALESINA \& SUMMERS, 1993), sendo este resultante da tendência à diminuição dos ganhos de senhoriagem e da capacidade do banco central em rejeitar o financiamento do déficit público, conforme apresentado nos estudos quantitativos e econométricos de Grilli et al (1991).

Para garantir o cumprimento das regras, sugere-se a criação de órgãos independentes, tais como os bancos centrais, não sujeitos ao poder discricionário de cada novo governo e às interferências políticas ad hoc em suas decisões operacionais (ALESINA, 1989). De acordo com essa interpretação, na ausência de um banco central independente que se guie por regras fixas e impessoais, o controle da economia pelos políticos conduziria à inconsistência e ao desequilíbrio macroeconômico. Mesma visão de Barro e Gordon (1983), que ressaltam o papel da reputação do governo sobre a política monetária como forma de disciplinar a sua condução.

Em que pese o fato de a escola novo-clássica ter sido a pioneira na defesa da IBC, a escola novo-keynesiana - corrente de pensamento econômico desenvolvido a partir dos anos 1980 em resposta aos novos-clássicos - também contribuiu substantivamente a favor dessa proposta. Diferentemente dos novos-clássicos, os novos-keynesianos admitem política monetária (e fiscal) ativa e a existência de rigidez de preços e de salários no curto prazo devido à presença de imperfeições de mercado (CLARIDA, GALÍ \& GERTLER, 1999; MISHKIN, 2000). Assim, no curto prazo prevalecem os pressupostos teóricos da teoria novo-keynesiana, enquanto no longo prazo prevalecem os da novo-clássica (MOREIRA, 2012).

Nesse ínterim, o regime de metas de inflação e a tese de IBC se consolidaram como propostas por meio de consensos entre as escolas novo-clássica e novo-keynesiana, culminando no arcabouço teórico conhecido como a nova síntese neoclássica, mainstream nas Ciências Econômicas atualmente. A defesa do regime de metas de inflação reforçou o apelo à adoção de um comprometimento com bancos centrais independentes (GOODFRIEND \& KING, 1997; WOODFORD, 2009), isso porque a nova síntese neoclássica supõe que a resposta ao ajuste da taxa de juros estabiliza ao mesmo tempo a inflação e o produto ao longo do tempo, sem custo ou perda para a dinâmica produtiva no longo prazo (MOREIRA, 2012).

Avaliando essas questões e influenciado por elas, Taylor $(1997,2000)$ sintetizou em cinco princípios o que considerou ser o núcleo duro da macroeconomia moderna e que deve tanto ser lecionado academicamente quanto aplicado pelos policy makers. São eles: a) o crescimento de longo prazo é determinado pelo lado da oferta por meio dos movimentos da função de produção; b) não há trade-off entre a taxa de inflação e a taxa de desemprego no longo prazo; c) há trade-off entre a taxa 
de inflação e a taxa de desemprego no curto prazo; d) as expectativas dos agentes respondem às decisões políticas, tais como a monetária e a fiscal; e) as políticas monetária e fiscal devem ser avaliadas com base em uma série de mudanças conectadas por um processo sistemático ou por uma regra, como a de Taylor (1993). Ressalta-se que o consenso da nova síntese neoclássica se configura no core da defesa da IBC.

\section{A necessidade de independência do Banco Central do Brasil: uma questão em aberto}

Consumada na seção anterior à exposição do arcabouço teórico que alicerça a proposta da IBC, essa seção é dedicada à discussão dos argumentos favoráveis e contrários a sua implementação, com ênfase no caso do BCB.

\subsection{Principais argumentos favoráveis à independência do BCB}

A característica preponderante da história do BCB foi a forte e permanente resistência a sua criação, sendo que o Brasil foi um dos últimos países do mundo a instituir seu banco central, o qual ainda teve de fazê-lo por etapas a partir de 1964 para que pudessem ser vencidas as forças contrárias ao seu surgimento. De lá para cá, a mudança histórica e institucional mais relevante no sentido de promover a independência do $\mathrm{BCB}$ ocorreu por ocasião da promulgação do decreto número 3.088, de 21 de junho de 1999 (BRASIL, 1999). O país veio a adotar a sistemática de metas de inflação como diretriz norteadora da condução da política monetária, cabendo a partir daquele momento explicitamente - de acordo com o artigo $2^{\circ}$ do referido decreto - ao $\mathrm{BCB}$ a responsabilidade de "executar as políticas necessárias para cumprimento das metas fixadas". Desde então, uma discussão fulcral quando se fala em BCB é a que se refere à real necessidade de ele ser ou não independente em sua tomada de decisões.

Há autores brasileiros que, em consonância com o arcabouço teórico da nova síntese neoclássica, defendem ser salutar ter o BCB independente. Esse é o caso de Troster (2003), que argumenta que a inflação é um freio para o crescimento sustentado do Brasil e limita fortemente seu potencial econômico, prejudicando todos os extratos produtivos, sobretudo os de menor poder aquisitivo. Mesmo assim, na opinião do autor, ainda há setores que são complacentes com a inflação e criam pressões políticas, perseguindo uma popularidade imediata em detrimento de benefícios duradouros para o conjunto da sociedade. A independência do $\mathrm{BCB}$ envolve pontos importantes e complexos, dos quais se destacam: a decisão sobre como alcançar a meta, a capacidade de operar os instrumentos financeiros, a autonomia orçamentária, a transparência, a governança, as relações do $\mathrm{BCB}$ com outras instituições e o 
papel de sua diretoria.

Convém lembrar que a independência, ainda de acordo com Troster (2003), refere-se tanto à proteção dos interesses do país quanto ao do governo empossado, implicitamente assumindo que ambos se confundem. Na prática, isso não acontece porque os interesses imediatos e pressões dos governantes muitas vezes contrapõem-se aos interesses duradouros da sociedade, ora sejam, crescimento sustentado e estabilidade.

Outro defensor da independência do BCB é Rigolon (1998), que parte de um argumento histórico para defender a independência do BCB. Ele atesta que a baixa independência e o alto ativismo da política monetária na década de 1980 e início dos anos 1990 resultaram no sacrifício permanente entre estabilidade de preço em troca de objetivos conflitantes de curto prazo no país, tais como emprego elevado, coleta de senhoriagem, equilíbrio do balanço de pagamentos e equilíbrio financeiro.

Além disso, a baixa independência do $\mathrm{BCB}$ e o alto ativismo monetário no período amplificaram a incerteza política e inflacionária, comprometendo a própria credibilidade da política monetária. A dificuldade de reversão das expectativas inflacionárias impôs grandes custos recessivos às tentativas de desinflação e diminuiu a eficácia e eficiência das políticas destinadas a expandir o emprego e equilibrar as finanças públicas. Todavia, o autor adverte que somente a independência do $\mathrm{BCB}$ não é condição suficiente para assegurar a manutenção de estabilidade de preços no longo prazo (RIGOLON, 1998).

Ainda nessa linha de raciocínio, Loyola (2003) acrescenta a importância do $\mathrm{BCB}$ como fator de credibilidade para os investidores estrangeiros, explicando que

é sabido que a autonomia do BCB é um tema particularmente sensível para os investidores estrangeiros, que prezam muito os avanços institucionais. Os investidores domésticos podem até relevar a inexistência de autonomia formal do BCB, em favor de uma autonomia de fato que se evidencie no dia a dia da política monetária. Os estrangeiros, contudo, poderão ter uma leitura muito negativa, caso fique patente a dificuldade de o governo encaminhar essa questão em sua base de apoio (O Estado de São Paulo, 30/03/2003).

Mais recentemente, o caso de maior repercussão nacional ocorreu no pleito para presidente da República em 2014, em que a discussão sobre a autonomia versus independência do $\mathrm{BCB}$ figurou como um dos temas centrais do debate eleitoral. Das três candidaturas mais votadas, na ordem, Dilma Rousseff, Aécio Neves e Marina Silva, essa última - amparada por sua equipe econômica - foi a que propôs a implementação formal da independência do $\mathrm{BCB}^{5}$, pretendendo assegurá-la "o mais

\footnotetext{
5 Cabe ressaltar que tanto no projeto de governo de Dilma Rousseff quanto no de Aécio Neves, não constavam propostas formais de independência do $\mathrm{BCB}$, mas sim de autonomia, de maior grau no segundo caso comparativamente ao primeiro.
} 
rapidamente possível, de forma institucional, para que ele possa praticar a política monetária necessária ao controle da inflação" (SILVA \& ALBUQUERQUE, 2014, p.46).

Segundo seus proponentes, o modelo seria mais bem detalhado caso a candidata fosse eleita, o que não foi o caso. Porém, transparecia advogar os pressupostos do arcabouço teórico da nova síntese neoclássica, ao expressar textualmente que haveria regras definidas e acordadas em lei, estabelecendo mandato fixo para o presidente, normas para sua nomeação e de diretores, regras de destituição de membros da diretoria, dentre outras medidas que garantissem juridicamente a independência do BCB (SILVA \& ALBUQUERQUE, 2014).

\subsection{Principais questionamentos à independência do Banco Central}

A literatura econômica apresenta uma série de argumentos que questionam a tese da IBC, especialmente provindos de correntes teóricas não mainstream. No caso brasileiro, destacam-se nessa seara autores alinhados à escola de pensamento econômico pós-keynesiana ${ }^{6}$. Essencialmente, esses buscam resgatar a interpretação do sistema capitalista como uma economia monetária de produção à la Keynes (1936, 1973), em que a moeda não é neutra nem no curto e nem no longo prazo, com que a política monetária afeta as variáveis nominais e reais da economia em um ambiente intrinsecamente incerto. Com efeito, a moeda e os arranjos institucionais financeiros e monetários têm papéis cruciais tanto no desenvolvimento como na instabilidade econômica.

Calcado nesses pressupostos teóricos, Mendonça (2003) afirma que as evidências empíricas favoráveis à IBC apontadas em estudos quantitativos e econométricos como os de Grilli et al (1991), Cukierman, Webb \& Neyapti (1992) e de Alesina \& Summers (1993) - citados na seção anterior - aplicam-se apenas às economias já industrializadas. Essas não se sustentam no caso de países em desenvolvimento, como o Brasil, já que a IBC "não é uma estrutura adequada para que economias emergentes encontrem o caminho da estabilidade". Dentre outras coisas, o arcabouço teórico da nova síntese neoclássica impede a possibilidade de "utilização da política monetária de forma contracíclica” (MENDONÇA, 2003, p. 119).

Além disso, Paula (2004) reforça que os estudos desenvolvidos até o momento na relação entre grau de IBC e baixa inflação carecem de base teórica sólida. Há países sem banco central independente, como o caso do Japão, que historicamente tem mantido a inflação baixa (por fatores não só correlacionados à condução da po-

6 A escola pós-keynesiana surgiu em meados da década de 1970, como uma reação crítica à nova síntese neoclássica. Seus autores mais influentes são Anthony Thirwall, Hyman Minsky, Jan Kregel, Philip Arestis, Paul Davidson e Victoria Chick. Para uma discussão pormenorizada sobre a construção histórica e o núcleo do programa de pesquisa pós-keynesiano, ver Carvalho (1992) e Oreiro (2011). 
lítica monetária, diga-se) e, há outros países, como os Estados Unidos, que embora possuindo um banco central independente, possuem objetivos múltiplos, que não consistem exclusivamente no combate à inflação?.

Paula (2004) acrescenta que o objetivo da política econômica brasileira deve ser a estabilidade macroeconômica, um conceito mais amplo do que o de estabilidade de preços, ou seja, deve procurar reduzir as incertezas que são inerentes aos negócios na economia. De acordo com essa interpretação, estabilidade de preços e aumento do produto e emprego podem ser compatíveis e, para que tal compatibilidade ocorra, o governo deve fazer uso ativo de um instrumental de política econômica mais amplo do que somente a política monetária.

Assim, Paula (2004) sustenta que para atingir objetivos múltiplos - como crescimento econômico e estabilidade de preços - é necessária a maior coordenação das políticas (fiscal, monetária, cambial e salarial), isto é, devem-se avaliar os impactos conjuntos da adoção de políticas sobre o conjunto de objetivos como um todo. Assim, a coordenação de políticas é fundamental para se atingir a almejada estabilidade macroeconômica. Desse modo, conclui o autor, a utilização de compromissos institucionais, como a independência do BCB, pode gerar problemas de descoordenação da política econômica.

Convergindo com o argumento anterior, Freitas (2006) também questiona à implementação da independência do BCB. Ela parte da constatação de que a economia brasileira ocupa uma posição periférica na hierarquia do sistema monetário e financeiro internacional, na qual o resgate da grande dívida social passa necessariamente pela retomada do crescimento e pela adoção de políticas ativas de emprego e renda. A autora afirma que

a adoção da estabilidade dos preços como objetivo único do banco central, como previsto no regime de metas de inflação, engessa toda a política econômica, impede a coordenação de políticas e retira do Executivo o poder de formular a política monetária. Nesse tipo de regime, todas as demais políticas tornam-se subordinadas à política monetária, potencializando os constrangimentos decorrentes da posição internacional periférica (FREITAS, 2006, p. 286).

No que se refere à posição periférica do Brasil no cenário econômico internacional, Oreiro, Sicsú \& Paula (2003) propõem uma estratégia alternativa à independência do BCB para o crescimento sustentado e financeiramente estável da economia brasileira, qual seja, passar por um esforço sistemático e planejado de diminuição da vulnerabilidade externa e da dependência em relação aos capitais estrangeiros. Uma estratégia desse tipo deve procurar compatibilizar equilíbrio interno com equilíbrio externo, de modo a superar o comportamento de stop-and-go e

\footnotetext{
O ciclo do produto real é uma das maiores preocupações especificamente no caso do banco central norte-americano.
} 
a tendência à semiestagnação que tem caracterizado a economia brasileira ao longo dos anos. Em concordância com a visão dos autores citados até aqui nessa subseção está Carvalho (1995, p. 140), o qual assevera que

\begin{abstract}
a tese da independência é [...] uma posição fundamentalmente derrotista, seja porque supõe que a estabilidade é algo a se forçar garganta abaixo, seja porque se imagine que processos democráticos são intrinsecamente irresponsáveis e desintegradores. Essa tese, porém, nem de longe esgota as possibilidades a serem consideradas dentro de uma estratégia de estabilização.
\end{abstract}

Outro questionamento quanto à instituição da independência do BCB diz respeito ao inconveniente da diluição da responsabilidade política pela condução da economia. Garagorry (2004), por exemplo, enfatiza que a política econômica é um fato bastante sensível para a sociedade como um todo. Seus resultados servem como principal critério para avaliar os governos, já que não raramente os objetivos e expectativas da sociedade são confundidos com os da própria política econômica. Por essa razão, geralmente ela ocupa o centro do debate dos processos eleitorais. Assim, a escolha dos governantes em grande medida deve-se à proposta de política econômica. A IBC em relação ao governo seria, portanto, incoerente com a chamada soberania democrática popular que se manifestaria no processo eleitoral. A rigor, nas palavras de Garagorry (2004, p. 9), tal proposta configurar-se-ia como um "estelionato eleitoral".

Garagorry (2004) questiona, ainda, como se poderia conciliar a ideia da soberania popular, enquanto ideologia básica do formalismo democrático, com a proposta de IBC. Essa leitura defende que nos países de regime democrático como o Brasil, ao se eleger um presidente, a maioria da população faz a opção, com maior ou menor clareza, por um programa de governo no qual estão contempladas metas econômicas. A representatividade obtida por meio do voto confere legitimidade às decisões governamentais. Em um contexto de banco central independente com poderes decisórios de política econômica, há grande risco de que um presidente recém-eleito se veja impossibilitado de implementar seu programa, frustrando as expectativas de seus eleitores se ele não concordar com a autoridade monetária.

Para além da discussão dicotômica entre favoráveis e contrários (ou questionadores) à independência dos bancos centrais em geral, e do BCB em particular, há ainda outros pesquisadores que advogam que não há grande diferença entre haver ou não IBC. Esse é o caso de Crocco \& Jayme Júnior (2003), por exemplo, que avaliam que se é o banco central que está determinando a taxa de juros e a taxa de câmbio, tanto faz se ele tem de atingir uma meta estabelecida pelo governo ou por ele próprio, pois sua ação sempre correrá o risco de se confrontar com a política fiscal (no caso de presença de dominância fiscal ${ }^{8}$, por exemplo), gerando sérios pro-

8 Relativo à Teoria Fiscal do Nível de Preços. Para uma abordagem aprofundada desse assunto, ver 
blemas de coordenação econômica.

Nesse ínterim, é importante enfatizar que as teorias econômicas adotadas por defensores ou não da proposta de independência dos bancos centrais têm papel determinante nesse debate que continua em aberto, apesar da possibilidade de alguns consensos de caráter mais geral. Assim, como aponta Moreira (2012, p. 101),

acredita-se que a prática da política monetária no mundo, bem como a prática de qualquer política pública, está permeada pelas impressões e resultados lançados pela teoria de cada momento. A despeito das controvérsias teóricas existentes, há um conjunto de elementos e consensos relativos que dominam e contextualizam as decisões de política dos conselhos diretores (monetary policy makers), seja no Brasil, seja em qualquer país que adote o receituário de estabilidade de preços como um dos pilares da política econômica.

\section{As relações do BCB com o governo e seus efeitos na condução da política monetária}

Diante do exposto, é importante investigar se houve pressões exercidas pelo governo sobre as decisões do $\mathrm{BCB}$ e, em caso afirmativo, de que forma elas influenciaram a condução da política monetária. Nesse sentido, examinam-se comparativamente as gestões de dois presidentes do $\mathrm{BCB}$, com ênfase para o período da troca entre eles à frente da instituição. Essa comparação transcorrerá via análise do discurso de agentes políticos e econômicos, elaborada com base em fontes acadêmicas e não acadêmicas (jornais, revistas, documentos do $\mathrm{BCB}$, etc.). Assim sendo, primeiramente será examinada a gestão de Henrique Meirelles, que comandou o $\mathrm{BCB}$ entre janeiro de 2003 e dezembro de 2010. Na sequência, será analisada a gestão de Alexandre Tombini, que presidiu o BCB entre janeiro de 2011 e junho de 2016.

\subsection{A gestão de Henrique Meirelles (2003-2010): uma autonomia operacional "total"}

O anúncio de Meirelles como presidente do BCB fez parte de uma estratégia para acalmar os mercados - sobretudo o das finanças - após a eleição de Luiz Inácio Lula da Silva para a presidência do Brasil. Ex-presidente mundial do Bank Boston e de visão econômica mainstream reconhecida no meio financeiro, Meirelles foi uma escolha que teve inicialmente o intuito de enfrentar o cenário conjuntural adverso daquele momento (risco-Brasil e taxa cambial e de juros bastante elevadas, por exemplo), cenário aquele decorrente especialmente da desconfiança derivada de bandeiras históricas defendidas até pouco antes do pleito por Lula e por seus correligionários, tais como a revisão das dívidas interna e externa e o rompimento

Sims (1994), Woodford (2001) e Cochrane (2001). 
com o Fundo Monetário Internacional (FMI) (WERNECK, 2014; LACERDA et al, 2013).

A estratégia de aplacar os humores dos mercados em poucos meses mostrou-se eficaz, alinhada ao discurso de que o novo governo empossado manteria os pilares econômicos mainstream do governo de Fernando Henrique Cardoso (1995-2002), sinalizando, inter alia, a postura autônoma que o BCB continuaria a ter na condução da política monetária. Mas a opção por Meirelles gerou resistências e pressões de vários segmentos durante seus oito anos como presidente do $\mathrm{BCB}$ (WERNECK, 2014; LACERDA et al, 2013). Para além das resistências partidárias, dois casos de reiteradas pressões sobre a gestão de Meirelles à época merecem destaque: o do vice-presidente da República, José Alencar (2003-2010), e o do ministro da Fazenda, Guido Mantega (2006-2014)9.

Praticamente durante todo o período em que exerceu a vice-presidência da República, José Alencar foi um crítico do expediente da alta taxa de juros levadas a cabo pelo BCB, argumentando que esta impedia que o setor produtivo crescesse com maior vigor. Essas críticas foram mais acentuadas especialmente em 2003 e entre 2007 e 2008, antes do início da crise financeira internacional. Logo no primeiro semestre do governo Lula, Alencar alegou que as decisões acerca da fixação da taxa de juros não vinham surtindo o efeito desejado de ensejar um novo ciclo de crescimento na economia brasileira.

Por conta de sua discordância com Meirelles, em 2 de junho de 2003 Alencar declarou à imprensa: "precisamos de uma decisão política, isso não é decisão para economista. Do ponto de vista de filosofia das taxas de juros, isso é decisão para ser tomada na esfera política, porque tecnicamente tem dado errado" (Reuters, $2 / 6 / 2003$ ). A despeito dessa e de outras declarações que o vice-presidente proferiu desde sua posse, o BCB não cedeu às pressões políticas e o Comitê de Política Monetária (Copom) manteve a taxa básica de juros da economia em $26,5 \%$ a.a. entre fevereiro e junho de 2003 (BRASIL, BCB, 2016a), patamar acima até mesmo das expectativas de mercado que o relatório Focus vinha divulgando para o mesmo período, entre $25,5 \%$ a.a. e $26 \%$ a.a. (BRASIL, BCB, 2016c).

Já um episódio marcante envolvendo Mantega quanto às decisões do $\mathrm{BCB}$ ocorreu em 22 de janeiro de 2007, quando externou de forma pública seu desejo de diminuição mais veloz da taxa básica de juros no Brasil. Declarou o então ministro da Fazenda: "o mercado está esperando uma redução da taxa Selic. Uma continuação, viu, Meirelles?” (Gazeta do Povo, 25/1/2007). Essa declaração aconteceu dois dias antes da $124^{a}$ reunião do Copom, em 24 de janeiro de 2007, que decidiu pela redução da taxa básica de juros de 13,25\% a.a. para 13\% a.a, conforme esperado pela

9 Guido Mantega assumiu como ministro da Fazenda em março de 2006 e permaneceu até dezembro de 2014, estendendo sua colaboração com o governo federal até o fim do primeiro mandato presidencial de Dilma Rousseff (a ser tratado na subseção seguinte). Antes de Mantega, o ministro da Fazenda entre janeiro de 2003 e março de 2006 foi Antonio Palocci, esse último mais afinado ao discurso de Henrique Meirelles. 
maioria dos agentes de mercado (BRASIL, BCB, 2016c).

Um dia após essa decisão do Copom, ao ser questionado sobre a possibilidade de sua declaração ter sido uma (tentativa de) interferência na política monetária, Mantega - ao lado de Meirelles - afirmou que havia sido uma "brincadeira" e que "o ministro da Fazenda não determina taxa de juro", mas disse também: "claro que ele [Meirelles] sabe que eu gostaria de cortes mais rápidos”, indicando esperar novas reduções nos meses seguintes. Meirelles, rechaçando a ideia de pressão do governo, contemporizou: "temos uma relação muito amigável. É bem-humorada. Estamos de completo acordo" (O Globo, 26/1/2007).

À medida que as críticas e as pressões foram se sucedendo, sem a desejada cedência do BCB, foram aumentando os boatos sobre a saída de Meirelles. O governo reiterava que essa hipótese não passava de pura especulação. Asseverou Mantega sobre o tema, em 7 de fevereiro de 2007: "não tem fundamento nenhum". Apesar disso, revelou que Meirelles estava insatisfeito, pois "quando começa a aparecer um boato como esse, é natural a pessoa ficar chateada", e que também "ficaria chateado se amanhã aparecesse a notícia de que o ministro da Fazenda está demissionário", completando dizendo ser "natural que o Banco Central faça um papel antipático. Se fosse simpático, agradando a todo mundo, talvez não cumprisse adequadamente a sua função. Mas vamos continuar baixando os juros" (Valor Econômico, 7/2/2007).

As pressões e as manifestações públicas de agentes do governo ao longo do ano de 2008 redundou no período da mais intensa resistência desses à condução da política monetária implementada pelo presidente do BCB, apontando para sua saída iminente. Dois excertos ilustram esse argumento, bem como explicam o porquê de Meirelles continuar no cargo:

(1) A manutenção de taxa de juros relativamente altas e a persistente apreciação do câmbio tornaram as relações entre a Fazenda e o Banco Central cada vez mais tensas. O Ministério da Fazenda passou a contestar tanto a política de metas para a inflação como a política cambial. Especialmente depois que o Banco Central, preocupado com a reaceleração da inflação, voltou a elevar a taxa de juros em meados de abril de 2008. Foi um momento em que o compromisso do governo com a estabilidade macroeconômica parecia ter quase desaparecido. Resistia com grande dificuldade, acuado num último reduto, no Banco Central, enfrentando a hostilidade ostensiva da Fazenda, da Casa Civil e de boa parte do resto do governo, em meio a notícias de que o presidente Henrique Meirelles estava prestes a ser substituído [...]. Não fosse a repentina injeção de prudência que adveio da apreensão com o agravamento da crise financeira mundial, esse derradeiro reduto poderia ter sido subjugado (WERNECK, 2014, p. 369).

(2) A atribuição de grau de investimento à dívida soberana do país, pelas agências de avaliação de risco, no início de maio de 2008, exatamente quando a permanência do presidente do Banco Central no cargo estava por um fio, é a melhor evidência de que as percepções externas continuavam dominadas por essa visão um tanto desatualizada 
da condução da política econômica. Curiosamente, foi a obtenção [...] dessa chancela externa que, subitamente, deu sobrevida a Henrique Meirelles e impediu que prosperassem as pressões pela sua substituição que vinham sendo feitas pelo Ministério da Fazenda e pela Casa Civil. O agravamento da crise externa acabaria por lhe dar sobrevida adicional, até o final do mandato presidencial, ainda que num quadro de permanente tensão entre o Banco Central e o Ministério da Fazenda (WERNECK, 2014, p. 374).

Meirelles resistiu no cargo, sem aparente cedência do $\mathrm{BCB}$, às pressões do governo, mesmo sob as constantes críticas e resistências. Disse o vice-presidente da República em 7 de agosto de 2008, por exemplo, ao discordar da opinião de Meirelles, que seria necessária a manutenção da política de juros altos para combater a inflação diante do recrudescimento da crise financeira internacional: "este é o caminho da morte" (Zero Hora, 7/8/2008). Cinco dias depois, em 12 de agosto de 2008, Alencar reiterou suas críticas afirmando: "o [Brasil] vai bem, apesar da política monetária e não graças a ela”. E acrescentou: "não podemos submeter a economia brasileira a uma competição desigual e isso está sendo feito por força dessa política monetária equivocada. Tem que mudar a política monetária, isso eu venho falando a vida inteira" (Zero Hora, 12/8/2016). Não houve réplica pública de Meirelles para as referidas contestações às decisões do BCB nesse momento. Vale lembrar que entre abril e agosto de 2008, o BCB elevou a taxa de juros em 2,5\%, de $11,25 \%$ a.a. para $13,75 \%$ a.a., respectivamente, mantendo-a nesse patamar até janeiro de 2009 (BRASIL, BCB, 2016a).

Em 9 de dezembro de 2008, Meirelles veio a público aclarar que as medidas do BCB tinham o intento de preservar os avanços sociais em meio a crise financeira mundial em curso. Disse o presidente do BCB na ocasião: "vamos continuar trabalhando, continuar fazendo o que for preciso para preservar as conquistas, principalmente as que representam os 41 milhões de brasileiros que cruzaram a linha da pobreza” (Folha de São Paulo, 9/12/2008). No dia seguinte, em entrevista exclusiva para a revista Isto É, ele, mais uma vez, defendeu a condução da política monetária do BCB e ponderou: "em todas as reuniões a que vou, os colegas de outros bancos centrais e banqueiros privados fazem fila para elogiar a ação do BC brasileiro”.

Pouco mais de um ano para o final de sua presidência, Meirelles disse em entrevista coletiva, concedida em 25 de agosto de 2009, que o BCB era totalmente autônomo e que as políticas econômicas teriam continuidade caso saísse da instituição, e diante do questionamento sobre a independência do BCB asseverou que

não me compete, como presidente do $\mathrm{BCB}$, opinar sobre qualquer projeto de lei que venha contemplar uma independência formal do BCB no futuro. O que eu posso dizer é que a independência operacional concedida pelo presidente Lula está funcionando muito bem (O Estado de São Paulo, 25/08/2009). 
Em suma, ao contrastar o discurso dos agentes políticos e econômicos com as práticas do $\mathrm{BCB}$ durante o período em que Meirelles esteve à frente da instituição, considera-se que as tentativas de interferência dos primeiros sobre as decisões do segundo pouco afetaram a condução da política monetária. Essa conclusão sustenta-se pelas manifestações públicas à época e pelo cruzamento delas com as ações concretas do BCB aqui apresentadas, além das declarações públicas do próprio Meirelles como na ocasião do anúncio oficial de Tombini como novo presidente do BCB. Disse Meirelles, em 24 de novembro de 2010, que acreditava na manutenção da autonomia da autoridade monetária, já que a instituição tinha tido nos anos anteriores "uma ação de sucesso [...], reconhecida mundialmente, baseada na autonomia” (Portal EBC, 24/11/2010). Perguntado pela revista Isto É Dinheiro, em primeiro de dezembro de 2010 , se sua saída poderia ter sido melhor coordenada, respondeu: "Pode-se dizer que foi o último disparo de fogo amigo. Mas é o preço que se paga pelo trabalho e pelas decisões que tomei”.

\subsection{A gestão de Alexandre Tombini (2011-2016): uma (quase) auto- nomia operacional?}

Com a saída de Meirelles em dezembro de 2010, Tombini, servidor público concursado do BCB desde 1998 e então diretor de Normas e Organização do Sistema Financeiro, assumiu a presidência da instituição em janeiro de $2011 \mathrm{com}$ a tarefa inicial de dar continuidade e aprofundar o trabalho do antecessor, como afirmado por ambos em manifestações públicas à época. Dessa forma, a gestão Dilma Rousseff iniciou seu mandato apontando o prosseguimento da política econômica implementada até então pelo governo de Luiz Inácio Lula da Silva.

Em entrevista coletiva realizada em 24 de novembro de 2010, logo após ser escolhido para presidir o $\mathrm{BCB}$, e nos moldes das declarações de seu antecessor, Tombini disse que: "ela [Dilma] me disse que nesse regime não há meia autonomia. É autonomia operacional total. Ela não quer nada menos que o Banco Central perseguindo a meta de inflação”. Por sua vez, Guido Mantega, mantido no Ministério da Fazenda no primeiro governo de Dilma Rousseff, declarou que não garantiria que cessaria os pedidos públicos de interferência na política de juros, assim como fizera enquanto Meirelles era presidente do BCB (O Globo, 24/11/2010).

Para um panorama mais amplo dessa realidade, o cruzamento de alguns dados com os fatos ocorridos na vida política e econômica do país nesse período faz-se oportuno. Para tanto, seguem duas tabelas: a primeira, mostrando a taxa básica de juros determinada no período compreendido entre o final da gestão de Meirelles - 8 de dezembro de 2010 - e a reunião realizada pelo Copom em 17 de abril de 2013; a segunda, referente ao histórico de metas para a inflação no Brasil, com foco especial na inflação efetiva anual verificada entre 1999 e 2015. 
Tabela 1 - Histórico das taxas básicas de juros fixadas pelo Copom (2010-2013)

\begin{tabular}{|c|c|c|c|}
\hline \multicolumn{2}{|c|}{ Reunião } & \multirow{2}{*}{ Período de vigência } & \multirow{2}{*}{ Meta Selic* (\% a. a.) } \\
\hline $\mathrm{n}^{\mathrm{O}}$ & Data & & \\
\hline $155^{\mathrm{a}}$ & $08 / 12 / 2010$ & $09 / 12 / 2010-19 / 01 / 2011$ & 10,75 \\
\hline $156^{\mathrm{a}}$ & $19 / 01 / 2011$ & 20/01/2011 - 02/03/2011 & 11,25 \\
\hline $157^{\mathrm{a}}$ & $02 / 03 / 2011$ & 03/03/2011 - 20/04/2011 & 11,75 \\
\hline $158^{\mathrm{a}}$ & $20 / 04 / 2011$ & $21 / 04 / 2011-08 / 06 / 2011$ & 12,00 \\
\hline $159^{\mathrm{a}}$ & $08 / 06 / 2011$ & 09/06/2011 - 20/07/2011 & 12,25 \\
\hline $160^{\mathrm{a}}$ & $20 / 07 / 2011$ & $21 / 07 / 2011-31 / 08 / 2011$ & 12,50 \\
\hline $161^{\mathrm{a}}$ & $31 / 08 / 2011$ & 01/09/2011 - 19/10/2011 & 12,00 \\
\hline $162^{\mathrm{a}}$ & $19 / 10 / 2011$ & 20/10/2011 - 30/11/2011 & 11,50 \\
\hline $163^{\mathrm{a}}$ & $30 / 11 / 2011$ & 01/12/2011 - 18/01/2012 & 11,00 \\
\hline $164^{\mathrm{a}}$ & $18 / 01 / 2012$ & $19 / 01 / 2012-07 / 03 / 2012$ & 10,50 \\
\hline $165^{\mathrm{a}}$ & $07 / 03 / 2012$ & 08/03/2012 - 18/04/2012 & 9,75 \\
\hline $166^{\mathrm{a}}$ & $18 / 04 / 2012$ & $19 / 04 / 2012-30 / 05 / 2012$ & 9,00 \\
\hline $167^{\mathrm{a}}$ & $30 / 05 / 2012$ & $31 / 05 / 2012-11 / 07 / 2012$ & 8,50 \\
\hline $168^{\mathrm{a}}$ & $11 / 07 / 2012$ & $12 / 07 / 2012-29 / 08 / 2012$ & 8,00 \\
\hline $169^{\mathrm{a}}$ & $29 / 08 / 2012$ & $30 / 08 / 2012-10 / 10 / 2012$ & 7,50 \\
\hline $170^{\mathrm{a}}$ & $10 / 10 / 2012$ & $11 / 10 / 2012-28 / 11 / 2012$ & 7,25 \\
\hline $171^{\mathrm{a}}$ & $28 / 11 / 2012$ & $29 / 11 / 2012-16 / 01 / 2013$ & 7,25 \\
\hline $172^{\mathrm{a}}$ & $16 / 01 / 2013$ & $17 / 01 / 2013-06 / 03 / 2013$ & 7,25 \\
\hline $173^{\mathrm{a}}$ & $06 / 03 / 2013$ & $07 / 03 / 2013-17 / 04 / 2013$ & 7,25 \\
\hline $174^{\mathrm{a}}$ & $17 / 04 / 2013$ & $18 / 04 / 2013-29 / 05 / 2013$ & 7,50 \\
\hline
\end{tabular}

* Sistema Especial de Liquidação e Custódia (Selic). A Meta Selic é a taxa básica utilizada como referência pela política monetária e é estabelecida pelo Copom.

Fonte: BRASIL, BCB, 2016a. Elaboração própria. 
Tabela 2 - Histórico de metas para a inflação no Brasil (1999-2017) $)^{10} 11$

\begin{tabular}{|c|c|c|c|c|c|c|c|}
\hline Ano & Norma & Data & $\begin{array}{c}\text { Meta } \\
(\%)\end{array}$ & $\begin{array}{c}\text { Banda } \\
\text { (p.p) }\end{array}$ & $\begin{array}{c}\text { Limite } \\
\text { inferior e } \\
\text { superior }(\%)\end{array}$ & $\begin{array}{c}\text { Inflação } \\
\text { efetiva } \\
\text { (IPCA \% } \\
\text { a.a.) }\end{array}$ & $\begin{array}{l}\text { Desvios em } \\
\text { relação } \\
\text { à meta }(\%)\end{array}$ \\
\hline 1999 & \multirow{3}{*}{ Resolução 2.615} & \multirow{3}{*}{$30 / 6 / 1999$} & 8 & 2 & $6-10$ & 8,94 & $+0,94$ \\
\hline 2000 & & & 6 & 2 & $4-8$ & 5,97 & $-0,03$ \\
\hline 2001 & & & 4 & 2 & $2-6$ & 7,67 & $+3,67$ \\
\hline 2002 & Resolução 2.744 & $28 / 6 / 2000$ & 3,5 & 2 & $1,5-5,5$ & 12,53 & $+9,53$ \\
\hline \multirow{2}{*}{2003} & Resolução 2.842 & $28 / 6 / 2001$ & 3,25 & 2 & $1,25-5,25$ & & \\
\hline & Resolução 2.972 & $27 / 6 / 2002$ & 4 & 2,5 & $1,5-6,5$ & 9,30 & $+5,30$ \\
\hline \multirow{2}{*}{2004} & Resolução 2.792 & $27 / 6 / 2002$ & 3,75 & 2,5 & $1,25-6,25$ & & \\
\hline & Resolução 3.108 & $25 / 6 / 2003$ & 5,5 & 2,5 & $3-8$ & 7,60 & $+2,10$ \\
\hline 2005 & Resolução 3.108 & $25 / 6 / 2003$ & 4,5 & 2,5 & $2-7$ & 5,69 & $+1,19$ \\
\hline 2006 & Resolução 3.210 & $30 / 6 / 2004$ & 4,5 & 2 & $2,5-6,5$ & 3,14 & $-1,36$ \\
\hline 2007 & Resolução 3.291 & $23 / 6 / 2005$ & 4,5 & 2 & $2,5-6,5$ & 4,46 & $-0,04$ \\
\hline 2008 & Resolução 3.378 & $28 / 6 / 2000$ & 4,5 & 2 & $2,5-6,5$ & 5,90 & $+1,40$ \\
\hline 2009 & Resolução 3.463 & $29 / 6 / 2007$ & 4,5 & 2 & $2,5-6,5$ & 4,31 & $-0,19$ \\
\hline 2010 & Resolução 3.584 & $1 / 7 / 2008$ & 4,5 & 2 & $2,5-6,5$ & 5,91 & $+1,41$ \\
\hline 2011 & Resolução 3.748 & $30 / 6 / 2009$ & 4,5 & 2 & $2,5-6,5$ & 6,50 & $+2,00$ \\
\hline 2012 & Resolução 3.880 & $22 / 6 / 2010$ & 4,5 & 2 & $2,5-6,5$ & 5,84 & $+1,34$ \\
\hline 2013 & Resolução 3.991 & $30 / 6 / 2011$ & 4,5 & 2 & $2,5-6,5$ & 5,91 & $+1,41$ \\
\hline 2014 & Resolução 4.095 & $28 / 6 / 2012$ & 4,5 & 2 & $2,5-6,5$ & 6,41 & $+1,91$ \\
\hline 2015 & Resolução 4.237 & $28 / 6 / 2013$ & 4,5 & 2 & $2,5-6,5$ & 10,67 & $+5,17$ \\
\hline 2016 & Resolução 4.345 & $25 / 6 / 2014$ & 4,5 & 2 & $2,5-6,5$ & 6,29 & $+1,79$ \\
\hline 2017 & Resolução 4.419 & $25 / 6 / 2015$ & 4,5 & 1,5 & $3,0-6,0$ & - & - \\
\hline 2018 & Resolução 4.499 & $30 / 6 / 2016$ & 4,5 & 1,5 & $3,0-6,0$ & - & - \\
\hline
\end{tabular}

Nota: dados ainda inexistentes para os anos de 2017 e 2018.

Fonte: BRASIL, BCB, 2016b.

A tabela 1 evidencia que o patamar das taxas básicas de juros fixadas pelo Copom em 2013 foi substancialmente menor em comparação com o início da série,

10 Uma Carta Aberta foi escrita pelo presidente do BCB e endereçada ao ministro da Fazenda em 21 de janeiro de 2013 porque a taxa de inflação medida por meio da variação do Índice de Preços ao Consumidor Amplo (IPCA) rompeu o limite do intervalo de tolerância de pontos percentuais acima da meta central estabelecida para o ano de 2002 (o teto superior era de 5,5\%, mas a inflação observada foi de 12,53\%). Estabeleceram-se, então, metas ajustadas de 8,5\% para 2003 e de 5,5\% para 2004.

11 Importante destacar que, desde 1999, quando o BCB adotou oficialmente o regime de metas de inflação, foram nos anos de 2001, 2002 e 2003 que a taxa de inflação anual acumulada respectiva a cada ano ficou oficialmente acima do limite superior dos valores estimados previstos, ou seja, entre o final do mandato de Fernando Henrique Cardoso e início do governo Lula. Depois disso, essa situação só voltou a ocorrer em 2015. 
apresentando queda pronunciada a partir de meados de 2011. Já a tabela 2 mostra que no final da gestão de Meirelles a inflação vinha numa trajetória crescente e corria-se o risco de a meta não ser cumprida já em 2011, primeiro ano do governo Dilma (conforme a coluna intitulada "Desvios em relação à meta"). Lembrando que, apesar de ainda ter ficado dentro da meta de 4,5\% - com tolerância de 2 p.p. para cima ou para baixo -, o IPCA de 2010 registrou alta acumulada de 5,91\% e foi o maior desde 2004. No ano de 2011 foi registrada inflação de $6,5 \%$, ou seja, chegou-se ao limite superior da meta. Em 2012, a inflação oficial registrada foi de $5,84 \%$, representando uma desaceleração ante 2011, mas novamente ficando acima do centro da meta perseguida pelo BCB.

Como medida inicial sob o comando de Tombini, visando a evitar que a inflação comprometesse o cumprimento da meta estabelecida para 2011, pode-se observar que na $156^{\mathrm{a}}$ reunião do Copom foi promovido um aumento da taxa básica de juros (ver tabela 1). A diretoria do BCB elevou a taxa básica de juros em 0,5 p.p. (para 11,25\% a.a.), maior patamar desde março de 2009. Na reunião seguinte, os juros foram elevados novamente em 0,5 p.p. (11,75\% a.a.), o maior nível desde os $12,75 \%$ de janeiro de 2009 . Em abril, novo ajuste para cima na Selic, dessa vez de 0,25 p.p., levando a meta para a marca de $12 \%$ ao ano. Com mais esse aumento, o Brasil seguiu na liderança dentre as taxas de juros reais mais elevados do mundo. $\mathrm{O}$ posto foi mantido depois das reuniões de junho e julho de 2011 do Copom, que promoveu mais dois aumentos sucessivos de 0,25 p.p. e levou a Selic para o nível de $12,5 \%$ a.a.

$\mathrm{Na} 161^{\text {a }}$ reunião do Copom, em 31 de agosto de 2011, a diretoria do BCB surpreendeu com um corte de 0,5 p.p. na Selic, que passou para $12 \%$ ao ano, enquanto que quase a totalidade dos agentes - segundo o Relatório de Mercado Focus do BCB, de 26 de agosto de 2011 - esperava sua manutenção em 12,5\% a.a. ou o seu aumento para $12,75 \%$ a.a. (BRASIL, BCB, 2016c). A justificativa dos diretores da autoridade monetária foi de que a crise internacional vivida por economias avançadas, como as dos países europeus, teria influência na economia brasileira. A decisão do BCB foi bastante criticada por diversos agentes públicos e privados (especialmente pelos analistas de mercado), que levantaram a hipótese de perda de autonomia da autoridade monetária, já que dias antes da opção pela redução dos juros, a presidente Dilma Rousseff havia afirmado que começava a ver a possibilidade de redução dos juros no Brasil. Disse a presidente antes da decisão do Copom:

nós queremos que, a partir desse momento, nós comecemos a ter no horizonte a possibilidade de redução dos juros no Brasil. Não posso dizer quando vamos ter isso, mas asseguro que nós abrimos caminhos para ter isso. Nós queremos que sejam juros cadentes (Bom Dia Brasil, 01/09/2011).

Após essa decisão do Copom, Guido Mantega rebateu as críticas de interferência política nas decisões do $\mathrm{BCB}$. Buscando afastar essa hipótese, o então minis- 
tro da Fazenda disse que "até outro dia o $\mathrm{BC}$ estava subindo juros e ninguém falava nada" e acrescentou que "o BC estava aumentando juros agradando ou não o governo porque ele tem suas avaliações do cenário internacional e toma suas decisões” (Gazeta do Povo, 2/9/2011).

Esse ciclo de queda das taxas básicas de juros continuou até outubro de 2012, quando a taxa caiu para 7,25\%, a menor da série histórica, sempre sob fortes e constantes críticas de intervenção do Executivo nas decisões do BCB. Somente em 17 de abril de 2013, em uma decisão sem viés e não unânime - seis dos integrantes do colegiado votaram a favor da alta e dois votaram pela manutenção da taxa -, a diretoria do BCB elevou a taxa Selic para 7,50\%. Segundo a Ata do Copom, a justificativa para a referida elevação veio com a afirmação da diretoria de que

\begin{abstract}
o nível elevado da inflação e a dispersão de aumentos de preços, entre outros fatores, contribuem para que a inflação mostre resistência e ensejam uma resposta da política monetária. Por outro lado, o Copom pondera que incertezas internas e, principalmente, externas cercam o cenário prospectivo para a inflação e recomendam que a política monetária seja administrada com cautela (BCB, Copom, $174^{\circ}$ Reunião, abril de 2013).
\end{abstract}

Nesse cenário, também no dia 17 de abril de 2013 e após as declarações de Tombini que à época disse "não há nem haverá tolerância com a inflação", o ministro da Fazenda expressou-se publicamente como segue: "posso dizer que mesmo as medidas que são consideradas menos populares são tomadas, por exemplo, em relação às taxas juros quando isso é necessário". E mais, nessa mesma semana, a presidente Dilma disse que qualquer necessidade de aumento de juros para combater a inflação naquele momento poderia ser administrada "em um patamar bem menor" do que quando o país conviveu com taxas mais altas (Revista Exame, 17/04/2013). Logo, esse foi um caso que denotou que houve influência do Executivo nas decisões do $\mathrm{BCB}$, uma vez que os atores do governo deixaram transparecer ao público suas opiniões a respeito das decisões que viriam a ser proferidas pelo $\mathrm{BCB}$ posteriormente, ao contrário do prognóstico geral dos diversos agentes, portanto.

Ainda em abril de 2013, a inflação medida pelo IPCA chegou a 6,59\% no cômputo acumulado dos doze meses anteriores, ultrapassando o teto da meta (6,5\%), o que reforçou a pressão para que o $\mathrm{BCB}$ elevasse os juros. As apostas dos agentes nesse sentido intensificaram-se - conforme os Relatórios de Mercado Focus do BCB, de abril de 2013 (BRASIL, BCB, 2016c) -, impulsionadas também por declarações de membros do governo como as elencadas no parágrafo anterior, prevendo um novo ciclo de aumentos da taxa Selic (G1, 10/4/2013).

O presidente do BCB repetiu o discurso diante da situação ao dizer que não haveria tolerância com a inflação. "Estamos neste momento monitorando atentamente todos os indicadores e, obviamente, no futuro, vamos tomar decisões sobre o melhor curso para a política monetária”. E a presidente Dilma endossou esse discurso, asseverando: "não fazemos concessão à inflação e sempre combatemos e 
combateremos a inflação, principalmente pelo mal que causa para trabalhadores e empresários. Corrói as rendas. Não abriremos mão desse controle" (O Estado de São Paulo, 17/4/2013).

Essa conjuntura não passou despercebida pelos agentes, pois as pressões políticas sofridas pelo $\mathrm{BCB}$ repercutiram de maneira negativa dentro e fora do país, especialmente na economia brasileira. Tanto foi assim que, por exemplo, a revista The Economist publicou um artigo em 2011 em que especulava se os então recentes e seguidos cortes na taxa de juros no Brasil prematuramente feitos logo no início da gestão Dilma, segundo a revista, poderiam sinalizar uma mudança nas prioridades do governo (privilegiando o crescimento e a prevenção da sobrevalorização da moeda, em vez de manter a inflação baixa) e a perda de autonomia do BCB, minando a credibilidade conquistada a longo do trabalho empreendido nos anos anteriores por Meirelles (BBC Brasil, 28/10/2013). Em 20 de abril de 2013, a própria revista The Economist publicou nova matéria, intitulada "Inflation in Brazil: behind the curve”, relacionando essa nova análise à feita em 2011, apontando que

the belated interest-rate rise suggests that the bank recognises it needs to regain some lost credibility. Its operational independence has been in question since August 2011, when it cut rates even though inflation had reached $7.1 \%$ - and kept cutting even though inflation remained above target. Dilma Rousseff, the president, has trumpeted low interest rates as a "conquest" by her government ever since. Days before the bank's monetary-policy meeting Guido Mantega, the finance minister, said that tackling inflation no longer required heavy artillery, as in the past. Many analysts have concluded that the government was pressing the bank to keep rates low, with an eye to supporting Brazil's weak economy.

Enfim, nota-se que além das opiniões gerais à proposta da independência do $\mathrm{BCB}$, há, no caso brasileiro, uma questão de fundo mais essencial, baseada nas interpretações dos discursos proferidos pelos dirigentes do banco central e dos órgãos do Executivo e Legislativo, relação essa entranhada nas instituições e nas próprias condições conjunturais e estruturais do Estado. Assim sendo, em uma análise que envolva o BCB deve-se também levar em conta os ciclos políticos do país, ou seja, a relação e a troca de pessoas eleitas nas funções para qual a população as escolheu para um determinado período de tempo.

Como apresentado, aparentemente Meirelles atuou com um grau maior de autonomia e esteve mais comprometido com a estabilidade de preços, sinalizando maior credibilidade ao mercado do que Tombini, havendo, de fato, diminuição da credibilidade e questionamentos quanto à autonomia decisória do BCB sob a gestão desse último, uma vez que não havia diferenças jurídicas no BCB em ambas as gestões. Isso corrobora com a visão de Rogoff (1985) - conforme exposto na seção 2 - de que indicar uma pessoa que tenha comprometimento com a estabilidade de preços para a presidência do $\mathrm{BCB}$ pode ser em si um mecanismo institucional 
que reduza o viés inflacionário e eleve a credibilidade da instituição e das políticas econômicas a serem implementadas por ela.

No entanto, oficialmente diz-se que a condução da política monetária do Brasil não está a cargo de nenhum grupo político eleito, mas sim do BCB. Ainda assim, diante desses e de outros fatos e versões que pululam na vida pública brasileira, é plausível questionar se os políticos eleitos - tanto no poder Executivo quanto do poder Legislativo - detêm influência sobre o BCB, sem importar o grau de autonomia deste. Essa influência pode ser exercida de várias maneiras, não só via discurso. Por exemplo, com a presença de pessoas do governo nas mesas de decisões, obrigações implícitas para o $\mathrm{BCB}$ acomodar políticas fiscais, contatos informais entre o Tesouro Nacional e o $\mathrm{BCB}$, pressão diretiva do chefe do Executivo sobre o $\mathrm{BCB}$, a prerrogativa de indicar o presidente e os diretores do $\mathrm{BCB}$, dentre outras.

\section{Considerações finais}

Conforme exposto ao longo do texto, não há evidências teóricas e empíricas, nem de que um banco central deve ser independente, nem do contrário. Também não é prudente afirmar que a independência de um banco central seja condição necessária e suficiente para evitar pressões políticas ou crises econômicas, além de sua condução autônoma não atender a condição de estabilidade dos preços. Somado a isso, as diferentes experiências em países diversos - mesmo que influenciados pela teoria econômica em voga - demonstram que o caminho para a estabilidade da economia em geral (e da política monetária em particular) não é único. Até mesmo uma identificação nítida e a mensuração da independência de um banco central são complicadas, resultantes do caráter individualizado dessas experiências, em que a independência assume graus distintos e a legislação não raramente se distancia da realidade.

Mais razoável parece ser a proposta de atingir a estabilidade dos preços por meio da formulação de políticas macroeconômicas consistentes intertemporalmente, o que, em termos teóricos, pode ocorrer tanto com independência do banco central, como com a coordenação da política econômica. A experiência brasileira contribui de forma original a esse debate ao mostrar que, em razão das condições institucionais e especificidades históricas que marcaram a atuação do BCB ao longo do tempo, a independência poderia diminuir a transparência e, consequentemente, a possibilidade de controle social sobre as decisões implementadas. A despeito dessa consideração, a discussão da independência do $\mathrm{BCB}$ da maneira como tem sido feita no país impõe a necessidade de fazer-se uma diferenciação entre a formulação e a execução da política econômica, sob o risco de que, justificando-se objetivar a estabilidade da moeda, institucionalizem-se práticas que deflagrem situações de ingovernabilidade da política macroeconômica, já que podem cercear a capacidade de ação do governo. 
Dado que a formulação dos objetivos econômicos é uma tarefa sobejamente política e por isso compete ao governo fazê-la, este deve buscar executá-la dentro de um projeto que integre e coordene todas as suas propostas. Já sua execução exige um conhecimento e/ou domínio específico, desde que subordinado e condicionado aos objetivos e às diretrizes determinadas pelos formuladores dessas políticas. $\mathrm{O}$ $\mathrm{BCB}$, na execução da política monetária, teria de atuar com independência especialmente em relação aos setores financeiro e privado. Logo, seria imperioso deliberar com zelo sobre as possíveis incompatibilidades futuras e prévias de seus dirigentes. Assim, ao invés de simplesmente conferir independência ao BCB para a formulação de políticas e fixação de regras para a política monetária, mais adequado parece ser normatizar claramente o relacionamento do setor privado e do governo com a autoridade monetária, estabelecendo-se regras institucionais que assegurem participação efetiva do BCB nas instâncias decisórias governamentais.

No que tange a investigação sobre as (tentativas de) pressões exercidas pelos poderes Executivo e Legislativo na comparação entre a gestão de Meirelles e de Tombini, pode-se aventar a real possibilidade de que isso tenha ocorrido, dados os exemplos citados e analisados nesse artigo. Essas pressões podem aparecer das mais variadas formas e não apenas via discurso, podendo ser algo bastante nocivo para o conjunto da sociedade. Pela investigação empreendida, aparentemente Meirelles atuou com um grau maior de autonomia e esteve mais comprometido com a estabilidade de preços, sinalizando mais credibilidade ao mercado do que Tombini, havendo de fato diminuição da credibilidade do $\mathrm{BCB}$ sob a gestão deste último, uma vez que não havia diferenças jurídicas no $\mathrm{BCB}$ em ambas as gestões.

Ademais, ao examinar as expectativas do mercado, verificou-se que Meirelles agiu dentro do que este esperava e, por vezes, até com maior rigor do que o esperado na condução da política monetária, com que suas decisões frequentemente foram na direção contrária ao desejado pelo governo. Já Tombini agiu em pelo menos duas oportunidades na direção oposta às expectativas dos agentes econômicos de mercado, com que coincidiu com as expectativas (e o discurso) dos agentes do governo. Por essas razões, questionou-se a autonomia da gestão de Tombini.

Por fim, cabe frisar que a disposição em conferir independência ao $\mathrm{BCB}$, para que seja capaz de formular a política monetária com o propósito exclusivo de estabilidade dos preços, está distante de ser um assunto meramente técnico ou apolítico como declaram seus defensores, o que não deve implicar necessariamente em pressões políticas deliberadas para atingir um interesse apenas de um grupo em particular. Esse, também, é certamente um assunto político que, como outro qualquer, resulta em escolhas que não são neutras em suas consequências sobre a economia e sobre os distintos grupos da sociedade brasileira. Tais decisões compõem o jogo político e sua dimensão deve ser colocada em destaque no debate, não se podendo deixar que suas implicações políticas continuem veladas como se relacionadas tão somente a questões consensuais e técnicas. 


\section{Referências}

ALESINA, A. Politics and business cycles in industrial democracies. Economic Policy, Cambridge University Press, n. 8, p. 57-87, April 1989.

ALESINA, A.; SUMMERS, L. Central Bank Independence and Macroeconomic Performance: some comparative evidence. Journal of Money, Credit and Banking, Ohio, v. 25, p. 151-162, May 1993. crossrefhttps://doi.org/10.2307/2077833

BARRO, J. B.; GORDON, D. B. Rules, discretion and reputation in a model of monetary policy. Cambridge: NBER Working Paper Series, n. 1079, p. 1-33, Feb. 1983.

BRASIL. Banco Central do Brasil (BCB). Atas do Copom, $174^{\circ}$ Reunião. Brasília, 16 e 17 de abril de 2013. Disponível em: <http://www.bcb.gov.br/?COPOM174>. Acesso em: 13 de maio de 2016.

BRASIL. Banco Central do Brasil (BCB). Histórico das taxas de juros fixadas pelo Copom e evolução da taxa Selic. Brasília, 2016a. Disponível em: <www.bcb.gov. br/?COPOM JUROS>. Acesso em: 28 de setembro de 2016.

BRASIL. Banco Central do Brasil (BCB). Histórico de metas para a inflação no Brasil. Brasília, 2016b. Disponível em: <http://www.bcb.gov.br/Pec/metas/TabelaMetas eResultados.pdf>. Acesso em: 10 de outubro de 2016.

BRASIL. Banco Central do Brasil (BCB). Focus - Relatório de Mercado. Disponível em: < https://www.bcb.gov.br/pec/GCI/PORT/readout/readout.asp >. Acesso em: 10 de outubro de 2016.

BRASIL. Estabelece a sistemática de "metas para a inflação" como diretriz para fixação do regime de política monetária e dá outras providências. Decreto n. 3088, de 21 de junho de 1999.

CARVALHO, F. J. C. Mr. Keynes and the Post Keynesians: principles of macroeconomics for a monetary production economy. Edward Elgar: Aldershot, 1992.

CARVALHO, F. J. C. A independência do banco central e a disciplina monetária: observações críticas. Revista de Economia Política, São Paulo, v. 15, n. 4, p. 134-141, out./dez. 1995. 
CLARIDA, R. GALÍ, J. GERTLER, M. The science of monetary policy: a New Keynesian perspective. Journal of Economic Literature, v. 37,p. 1661-1707, Dez. 1999.

COCHRANE, J. Long-Term Debt and Optimal Policy in the Fiscal Theory of the Price Level. Econometrica, 69(1), p. 69-116, 2001. crossref https://doi. org/10.1111/1468-0262.00179

CROCCO, M.; JAIME JUNIOR, F. G. Independência e autonomia do banco central: mais sobre o debate. Belo Horizonte: UFMG/Cedeplar, texto 199, p. 1-17, maio 2003.

CUKIERMAN, A.; WEBB, S.; NEYAPTI, B. Measuring the independence of central banks ans its effects on policy outcomes. World Bank Economic Revierw. S. 1: v. 6, n. 6, p. 353-398, Sept. 1992.

FREITAS, M. C. P. Banco Central independente e coordenação das políticas macroeconômicas: lições para o Brasil. Economia e Sociedade, Campinas, v. 15, n. 2 (27), p. 269-293, ago. 2006.

GARAGORRY, J. A. S. A independência do Banco Central em debate. Lutas Sociais (PUCSP), São Paulo, v. 11/12, p. 10-22, 2004.

GOODFRIEND, M.; KING, R. G. The Ner Neoclassical Synthesis and the Role of Monetary Policy. In: BERNANKE, B.; ROTEMBERG, J. (Ed.). NBER Macroeconomics Annual, NBER Chapters, Cambridge: MIT Press, 12: 231-83, 1997.

GRILLI, V.; MASCIANDARO, D.; TABELLINI, G.; MALINVAULD, E.; PAGANO, M. Political and monetary institutions and public financial policies in the industrial countries. Economic Policy, v. 6, n. 13, p. 341-392, Oct. 1991. crossref https://doi.org/10.2307/1344630

KEYNES, J. M. The General Theory of Employment, Interest and Money. London: Macmillan Press; New York: St. Martin's Press, 1936.

KEYNES, J. M. The collected writings of John Maynard Keynes. Cambridge: Macmillan, 1973.

KYDLAND, F. E.; PRESCOTT, E. C. Rules rather than Discretion: the Inconsistency of Optimal Plans. Journal of Political Economy, 85, P. 473-491, June 1977. 
LACERDA, A. C.; REGO, M.; MARQUES, R. M.; SERRA, R. A. M. Economia brasileira. LACERDA, A. C. et al (Orgs.). $5^{\text {a }}$ ed. São Paulo: Saraiva, 2013.

LOYOLA, G. Artigo 192 - hesitações repercutem em expectativas. O Estado de São Paulo, São Paulo, 30 mar. 2003.

MENDONÇA, H. F. Independência do banco central e coordenação de políticas: vantagens e desvantagens de duas estruturas para estabilização. Revista de Economia Política, v. 23, n. 1 (89), jan./mar. 2003.

MISHKIN, F. S. Issues in Inflation Targeting. Paper presented at the Bank of Canada Conference, Price Stability and the Long-Run Target for Monetary Policy, p. 203-222, June 8-9, 2000.

MOREIRA, R. R. Revisitando as críticas Pós-Keynesianas à Nova Síntese Neoclássica: questões de política monetária. Análise Econômica, Porto Alegre, ano 29, n. 57, p. 77-105, mar. 2012.

OREIRO, J. L.; SICSÚ, J.; PAULA, L. F. Controle da dívida pública e política fiscal: uma alternativa para um crescimento auto-sustentado da economia brasileira. In: SICSÚ, J.; OREIRO, J. L.; PAULA, L. F. (Orgs.). Agenda Brasil: políticas econômicas para o crescimento com estabilidade de preços. Barueri/SP: Manole, p. 117-152, 2003.

OREIRO, J. L. Economia Pós-Keynesiana: origem, programa de pesquisa, questões resolvidas e desenvolvimentos futuros. Ensaios FEE, v. 32, n. 2, p. 283-312, nov. 2011.

PAULA, L. F. R. A questão da autonomia do banco central: uma visão alternativa. Indicadores Econômicos FEE, Porto Alegre, v. 32, n.1, p. 253-264, 2004.

RIGOLON, F. J. R. Independência do banco central: teoria e aplicações para o Brasil. Pequisa e Planejamento Econômico, Rio de Janeiro, v. 28, n. 2, p. 399-432, ago. 1998.

ROGOFF, K. The optimal degree of commitment to an intermediate monetary target. Quarterly Journal of Economic, n. 100, p. 1169-1190, Nov. 1985.

SILVA, M.; ALBUQUERQUE, B. Plano de governo: plano de ação para mudar o Brasil. 2014. Disponível em: <http://marinasilva.org.br/programa/\#pagina-38>. Acesso em: 2 out. 2016. 
SIMS, C.A. A simple model for study of the price level and the interaction of monetary and fiscal policy. Economic Theory, 4(3), p. 381-99, 1994. crossrefhttps:// doi.org/10.1007/BF01215378

TAYLOR, J. B. Discretion versus policy rules in practice. Carnegie-Rochester Conference Series on Public Policy, North-Holland, 39, p. 195-214, 1993.

TAYLOR, J. B. A core of practical macroeconomics. American Economic Review, v. 87, n. 2, p.233-235, 1997.

TAYLOR, J. B. Teaching modern macroeconomics at the principles level. American Economic Review, v. 90, n. 2, p.90-94, 2000. crossref https://doi.org/10.1257/ aer.90.2.90

TROSTER, R. L. A miopia e a autonomia. Tendências/Debates: o Banco Central deve ser autônomo? Folha de São Paulo, edição de 12/04/2003.

WALSH, C. Optimal contracts for central bankers. American Economic Review, New York, v. 85, n.1, p. 150-167, March 1995.

WERNECK, R. L. F. Alternância política, redistribuição e crescimento, 2003-2010. In: ABREU, M. P. (Org.). A ordem do progresso: dois séculos de política econômica no Brasil. $2^{a}$ ed. Rio de Janeiro: Elsevier, 2014, p. 357-430.

WOODFORD, M. Fiscal Requirements for Price Stability. Journal of Money, Credit and Banking, 33(3), p. 669-728, 2001. crossref https://doi.org/10.2307/2673890

WOODFORD, M. Convergence in Macroeconomics: Elements of the New Synthesis. American Economic Journal: Macroeconomics, 1 (1): 267-79, Jan. 2009. crossref https://doi.org/10.1257/mac.1.1.267

. Alencar quer decisão política para taxa de juros sem pirraça. Reuters, Brasília, 2 jun. 2006. Disponível em: < http://noticias.uol.com.br/ultnot/reuters/2003/06/02/ult27u35823.jhtm>. Acesso em: 10 de outubro de 2016.

. Sem unanimidade, Selic cai 0,25 ponto. Gazeta do Povo, Curitiba, 25 jan. 2007. Disponível em: <http://www.gazetadopovo.com.br/economia/sem-unanimidade-selic-cai-025-ponto-aci84qgb 5rpe3wcmzOsx1lob2>. Acesso em: 11 de outubro de 2016.

. Mantega e Meirelles negam divergência sobre juro. O Globo, Rio de Janeiro, 26 jan. 2007. Disponível em: <http://oglobo.globo.com/economia/ mantega-meirelles-negam-divergen cia-sobre-juro-4237915>. Acesso em: 11 de outubro de 2016. 
. Mantega nega saída de Meirelles e diz que governo não usará "artificialismo" no câmbio. Valor Econômico, 7 fev. 2007. <http://g1.globo.com/Noticias/Economia_Negocios/0,_AA1449100-9356,00-MANTEGA+NE GA+SAID $\mathrm{A}+\mathrm{DE}+\mathrm{MEIRE} \bar{L} L E S+\mathrm{E}+\mathrm{DIZ}+\mathrm{QUE}+\mathrm{GOVERNO}+\mathrm{NAO}+\mathrm{USARA}+\mathrm{ARTI}$ FICIALISMO+.html>. Acesso em: 11 de outubro de 2016.

. Política de juros altos "é o caminho da morte", diz Alencar. Zero Hora, 7 ago. 2008. Disponível em: <http://zh.clicrbs.com.br/rs/noticia/2008/08/ politica-de-juros-altos-e-o-caminho-da-morte-diz-alencar-2102657.html>. Acesso em: 11 de outubro de 2016.

. José Alencar: Brasil vai bem, apesar da política monetária. Zero Hora, Porto Alegre, 12 ago. 2008. Disponível em: < http://zh.clicrbs.com.br/rs/noticia/2008/08/jose-alencar-brasil-vai-bem-apesar-da-politica-monetaria-2115373. html>. Acesso em: 11 de outubro de 2016.

. Meirelles diz que governo tomará medidas para preservar conquistas sociais. Folha de São Paulo, São Paulo, 9 dez. 2008. Disponível em: <http:// www1.folha. uol.com.br/paywall/signup.shtml?http://www1.folha.uol.com.br/ mercado/2008/12/476871-me irelles-diz-que-governo-tomara-medidas-para-preservar-conquistas-sociais.shtml>. Acesso em: 12 de outubro de 2016.

. Henrique Meirelles. Isto É, São Paulo, 10 dez. 2008, Comportamento. Disponível em: <http://www.cartacapital.com.br/revista/795/uma-ideia-genial-3554.html>. Acesso em: 11 de outubro de 2016.

Meirelles diz que independência do Banco Central funciona bem. O Estado de São Paulo, São Paulo, 25 ago. 2009, Caderno de Economia. Disponível em: <http://www.estadao.com.br/noticias/economia,meirelles-diz-que-independencia-do-banco-central-funciona-bem,424434,0.htm> Acesso em: 10 de maio de 2016.

. Meirelles espera que próximo governo mantenha autonomia do Banco Central. Portal EBC, Brasília, 24. nov. 2010. Disponível em: <http://memoria.ebc.com.br/ agenciabrasil/noticia/2010-11-24/meirelles-espera-que-proximo-governo-mantenha-autonomi a-do-banco-central $>$. Acesso em: 13 de outubro de 2016.

. Dilma prometeu autonomia total ao BC, diz Tombini. O Globo, Rio de Janeiro, 24 nov. 2010, Economia e Negócios. Disponível em: <http://g1.globo. com/economia-e-negocios/noticia/2010/11/dilma-prometeu-autonomia-total-ao-bc-diz-tombini.html>. Acesso em: 9 de outubro de 2016.

. Banco Central: a missão e a independência. Revista Exame, 25 nov. 2010, Caderno Brasil. Disponível em: < http://exame.abril.com.br/brasil/noticias/ banco-central-a-missao-e-a-independencia >. Acesso em: 07 de outubro de 2016. 
. O adeus e o destino de Meirelles. Isto É Dinheiro, São Paulo, 1 dez. 2010. Disponível em: < http://www.istoedinheiro.com.br/noticias/econo$\mathrm{mia} / \mathrm{lista} / 4033>$. Acesso em: 13 de outubro de 2016.

. Banco Central surpreende mercado e reduz taxa de juros. Bom dia Brasil, Rio de Janeiro, 1 set. 2011. Disponível em: < http://g1.globo.com/bom-dia-brasil/noticia/2011/09/banco-central-surpreende-mercado-e-reduz-taxa-basica-de-juros.html>. Acesso em: 9 de outubro de 2016.

. Mantega rebate críticas do mercado ao Banco Central. Gazeta do Povo, Curitiba, 2 set. 2011, Economia. Disponível em: <http://www.gazetadopovo.com.br/ economia/mantega-rebate-criticas-do-mercado-ao-banco-central-bd89k5dum7c90s7fvylk0bo zy>. Acesso em: 9 de outubro de 2016.

. Monetary policy: work with me here. The Economist, São Paulo, 28 out. 2011. Disponpivel em: < http://www.economist.com/blogs/freeexchange/2011/10/monetary-policy-43>. Acesso em: 15 de maio de 2016.

. Inflação oficial acumula alta de 6,59\% em 12 meses, mostra IBGE. G1, São Paulo, 10 abril 2013. Disponível em: <http://g1.globo.com/economia/ noticia/2013/04/ inflacao-oficial-acumula-alta-de-659-em-12-meses-mostra-ibge. html>. Acesso em: 10 de outubro de 2016.

. BC volta a subir o juro após quase dois anos: Selic vai a 7,5\% ao ano. O Estado de São Paulo, São Paulo, 17 ab. 2013, Caderno de Economia. Disponível em: <http://economia.estadao.com.br/noticias/economia-geral,bc-volta-a-subir-o-juro-apos-quase-dois-anos-selic-vai-a-75-ao-ano,151048,0.htm >. Acesso em: 15 de maio de 2016.

. Copom sobe juros para 7,50\% ao ano. Revista Exame, 17 ab. 2013, Caderno de Economia. Disponível em: < http://exame.abril.com.br/economia/noticias/copom-sobe-juros-para-7-50-ao-ano>. Acesso em: 15 de maio de 2016.

Inflation in Brazil: behind the curve. The Economist, São Paulo, 20 ab. 2013. Disponível em: <http://www.economist.com/news/americas/21576417-central-bank-acts-belatedly-bring-prices-back-under-control-behind-curve $>$. Acesso em: 15 de maio de 2016.

Recebido em 17.06.16

Aprovado em 05.05.17 
